\title{
Technology-Rich Inquiry Science in Urban Classrooms: What are the Barriers to Inquiry Pedagogy?
}

\author{
Nancy Butler Songer, Hee-Sun Lee, Rosalind Kam \\ University of Michigan, Ann Arbor, MI, 48109-1259
}

Received 18 May 2001; Accepted 6 July 2001

\begin{abstract}
What are the barriers to technology-rich inquiry pedagogy in urban science classrooms, and what kinds of programs and support structures allow these barriers to be overcome? Research on the pedagogical practices within urban classrooms suggests that as a result of many constraints, many urban teachers' practices emphasize directive, controlling teaching, that is, the "pedagogy of poverty" (Haberman, 1991), rather than the facilitation of students' ownership and control over their learning, as advocated in inquiry science. On balance, research programs that advocate standards-based or inquiry teaching pedagogies demonstrate strong learning outcomes by urban students. This study tracked classroom research on a technology-rich inquiry weather program with six urban science teachers. The teachers implemented this program in coordination with a district-wide middle school science reform. Results indicated that despite many challenges in the first year of implementation, students in all 19 classrooms of this program demonstrated significant content and inquiry gains. In addition, case study data comprised of twice-weekly classroom observations and interviews with the six teachers suggest support structures that were both conducive and challenging to inquiry pedagogy. Our work has extended previous studies on urban science pedagogy and practices as it has begun to articulate what role the technological component plays either in contributing to the challenges we experienced or in helping urban science classrooms to realize inquiry science and other positive learning values. Although these data outline results after only the first year of systemic reform, we suggest that they begin to build evidence for the role of technology-rich inquiry programs in combating the pedagogy of poverty in urban science classrooms. (๑) 2002 John Wiley \& Sons, Inc. J Res Sci Teach 39: 128-150, 2002
\end{abstract}

\section{Introduction}

Between the fourth and eighth grades, American students' achievement and understanding of complex science decline relative to their peers internationally (Linn et al., 2000). For urban

\footnotetext{
Any opinions, findings, and conclusion or recommendations expressed in this article are those of the authors and do not necessarily reflect the views of the National Science Foundation.

Contract grant sponsor: National Science Foundation; Contract grant numbers: REC-9896054, REC-9805472.

Correspondence to: Nancy Butler Songer; E-mail: songer@umich.edu
} 
students these gaps are even more pronounced, such as in high-poverty urban Detroit, Michigan, where standardized test scores are among the nation's lowest. In one approach to addressing this issue, a technology-rich, inquiry-focused science program called Kids as Global Scientists: Weather (KGS; Songer et al., 1999) was developed, refined, and researched with tens of thousands of students nationwide, then recently customized for the needs of thousands of students and teachers in Detroit public schools. This article documents the patterns that occurred after the first year of this adaptation to a specific set of classrooms, including both successes and challenges within student achievement and factors favorable to inquiry pedagogy among 19 middle school classes taught by six teachers in Detroit public schools. Our focus question included: What are the barriers to technology-rich inquiry pedagogy in urban science classrooms?

\section{Urban Science Education}

Recent research indicates that when struggling to implement reform science programs, students and teachers in urban settings face many barriers, several of which are distinct from the barriers experienced by their colleagues in suburban and rural settings. Atwater \& Wiggins, (1995) reported that although a majority of urban African American students hold favorable attitudes toward science careers, only a small percentage $(25 \%)$ hold favorable attitudes toward classroom science. Barton (1998) argued that policy documents that advocate "science for all" do not consider the multiple realities of many participants, such as students in poverty. Barton further argued that because of this discontinuity between the realities of classroom science and the lives of many science students, it should not be surprising that urban students often do not find science to be interesting or relevant to their lives.

Other researchers have provided additional explanations for the challenges faced by urban science students. Haberman (1991) argued that urban teachers have tremendous constraints on their teaching, including large class sizes, inadequate prep time, lower levels of training, inadequate classroom space, and outdated materials, and that often these constraints result in a "directive, controlling pedagogy" (p. 291) that he called the pedagogy of poverty. This pedagogy is characterized by teacher-controlled activities such as giving information, tests, directions, and grades; monitoring seat work; settling disputes; and reviewing tests and homework. This pedagogy of poverty also includes a set of beliefs, such as "teachers are in charge and responsible," that often run counter to those that support inquiry science and those that motivated these individuals to become teachers in the first place. Haberman argued that pedagogy-of-poverty teaching practices are so common in urban classrooms that "a teacher in an urban school of the 1990s who did not engage in these basic acts as the primary means of instruction would be regarded as deviant" (p. 291).

Similarly, Teel, Debruin-Parecki, and Covington (1998) observed that "one of the most important causes of African American students' low achievement in school is inappropriate teaching strategies which make it difficult for them to reach their full potential, thus alienating them from school" (p. 480). As a result, Teel et al. (1998) designed a set of alternative teaching strategies based on motivation and school-failure theories. Two cohorts of urban African American middle school students were followed through activities designed to promote increased responsibility, student choice, and noncompetitive grading, and the results demonstrated successful improvements in both attitudes and performance. In another recent study Kahle, Meece, and Scantlebury (2000) designed a program of standards-based teaching that resulted in improvements in urban African American students' attitudes and performance in science. 
In summary, a set of recent studies on urban science education has indicated that the conditions common in urban science classrooms often result in pedagogical approaches that are unlikely to promote student ownership of knowledge, increased student responsibility for learning, and questioning. In the national science standards (National Research Council, 1996) these thinking skills are described as essential components of scientific inquiry-a kind of scientific thinking that the standards advocate as a foundational component of scientific literacy. Therefore, the profile of urban classroom pedagogy presented by Haberman (1991) and others suggests it is unlikely that most urban science students are experiencing opportunities for scientific inquiry in their classrooms and therefore are not being allowed opportunities to develop foundational thinking skills for scientific literacy. On balance, several studies in urban science classrooms that implement science pedagogy more in line with scientific inquiry such as standards-based teaching (Kahle et al., 2000) demonstrate significant gains in student attitudes and performance. The goal of this study was to continue to explore the barriers to fostering scientific inquiry in urban science classrooms through research on the implementation of a technology-rich, inquiry-focused weather program. We worked to build on what others know about the pedagogical approaches that foster productive and engaged scientific thinking among urban students, as well as on our eight years of iterative research on the Kids as Global Scientists: Weather (KGS) program, which has been shown to foster inquiry and rich content understanding among tens of thousands of students nationwide (Songer, 1996, 1998).

\section{Why Study Programs in Urban Settings That Embrace New Technologies?}

Although much media attention has been directed toward documenting the "digital divide," little research has been conducted to assess what accounts for these discrepancies or how these patterns can be overcome. The digital divide refers to differences between the information haves and have-nots-in other words, the documented differences that exist in computer access and use by race, particularly among K-12 students (Hoffman \& Novak, 1999). Although studies so far have merely documented demographic patterns, it has been suggested in recent studies that the gaps between races in the level of computer ownership and Internet access are increasing rather than diminishing. These gaps are increasing even within a technological climate in which nearly $100 \%$ of public schools have access to networks and computers and practically all other major institutions, such as those in business and medicine, are witnessing dramatic transformations catalyzed by technological innovations.

Research on students' use of technology also reveals differences in use by school socioeconomic status (SES). A national study by Becker (2000) documented that students in lowincome areas often use computers for repetitive activities, whereas students in high-income areas often use technology for higher-order thinking, problem solving, and other intellectually challenging activities. Similarly, teachers in low SES schools are more likely to use technology for repetitive practices, whereas teachers in high SES schools are more likely to use technology to foster creativity or problem solving (Becker \& Riel, 2000). Interestingly, although Becker and Riel's data were collected under completely different circumstances from those discussed by Haberman (1991), the practices observed in the more recent Becker study suggest that the pedagogy of poverty continues to thrive, even in urban classrooms embracing new technologies. In an address to the National Education Summit, then-U.S. president Clinton (1999) referred to the digital divide in both access and practices, stating, "The problem now is that the economy has changed much faster than the schools. People used to say, 'You know, the schools just aren't what they used to be.' The problem may be that too many of our 
schools are too much like they 'used to be,' but the world the children move out into is not at all as it used to be.... We've got the give the schools the tools they need to do the job."

In this article we outline an approach to educational reform that aims to provide students currently classified as digital-divide have-nots with what we believe are "the tools they need to do the job" - a technology-rich science program that encourages many dimensions of scientific inquiry including the analysis and synthesis of data, the generation of arguments and explanations to complex science questions, and the communication of science explanations to others.

\section{Why an Inquiry Approach to Challenge the Pedagogy of Poverty?}

In our view, inquiry science is an important approach for confronting the pedagogy of poverty for several reasons. First, inquiry approaches foster the development of deep foundational knowledge in a content area (Bransford, Brown, \& Cocking, 2000), a depth of understanding often not possible through directive, controlling teaching. Many current policy documents recognize the value of deep knowledge understanding in their declaration of inquiry thinking as a foundational component of scientific literacy (National Research Council, 1996). Second, inquiry thinking allows students to build on and expand their own natural problemsolving abilities (Bransford et al.). This allows urban students to find greater congruence between classroom science and their own lives, an opportunity not common for many (Barton, 1998). Third, programs that foster scientific inquiry often provide more challenging learning opportunities while also providing supports that allow such challenging learning to be realized (Bransford et al.). Many classrooms experiencing the pedagogy of poverty limit students' learning potential through low expectations and uniform assignments to all students. Fourth, inquiry programs recognize the importance of student ownership of their own knowledge, as well as the value of effective guidance and modeling of the development of foundational understandings in science by teachers. In contrast, the pedagogy of poverty sees teachers as "in charge" of all aspects of the learning process. Children often come to the learning environment enthusiastic to learn, and inquiry programs can more appropriately encourage, guide, and support students' learning attempts (Bransford et al.). For more information on the dimensions of inquiry advocated by the KGS program and their alignment with the national science standards, see Table 1.

\section{Why "Inside-Out" Urban Science Reform?}

Many educational researchers believe in the importance of current reforms, including Slavin (1996) who wrote, "Never in the history of American education has the potential for fundamental reform been as great (p. 2)." Others are more specific about the role of technology in reform, explaining that because technology is already a part of our lives, it should be embraced as the vehicle for societal transformation and as a means of changing both the "what" that students learn and the "how" that it should be accomplished (Pea, 1998).

For the past 100 years, American educational reform has been ardently pursued but with a varied range of goals. Despite a range of approaches (i.e., top-down mandates or bottom-up approaches), levels of focus (i.e., national, state, or district level) and agents of change (i.e., intended curricula or professional development), most accounts of educational reform have concluded that these efforts have achieved mixed results (Knapp, 1997) and that gradual changes have, according to some experts, only "added complexity" to a highly complex system (Tyack \& Cuban, 1995, p. 83). 
Table 1

The KGS curriculum and the national science education standards, National Research Council (1996)

NSES Standard and Fundamental

Concepts

KGS Learning Activities

Phase

Science as Inquiry

Content Standard A: All students should develop the abilities necessary to do scientific inquiry and understandings about scientific inquiry. (p. 143)

- Identify questions that can be answered through scientific

- Exchange information and data with other

All phases investigations sites, develop questions and predictions.

Physical Science

Content Standard B: All students should develop an understanding of transfer of energy. (p. 149)

- Energy is associated with many

- Tornado in a bottle experiment. substances, including mechanical motion, and is transferred in many ways.

Earth and Space Science

Content Standard D: All students should develop an understanding of the: (a) structure of the earth system and (b) earth in the solar system. (p. 158)

- Global patterns of atmospheric movement influence local weather. Oceans have a major effect on climate because water in the oceans holds a large amount of
- Compare weather data from different geographical sites and explain similarities and differences.

- Report currently occurring severe weather worldwide.
Any phase heat.

Science in Personal and Social Perspectives

Content Standard F: All students should develop understanding about (a) natural hazards, (b) risks and benefits, and (c) science and technology in society. (p. 166)

- Processes of the earth system cause natural hazards, events that change or destroy human and wildlife habitats, damage property, and harm or kill humans. Natural

- Report a current severe storm (descriptions of severe weather: floods,

Any phase blizzards, storms, especially those that are experienced locally). hazards include floods and storms.

History and the Nature of Science

Content Standard G: All students should develop understanding of (a) science as a human endeavor, and (b) the nature of science. (p. 170)

- Women and men of various social and ethnic backgrounds engage in the activities of science. Some scientists work in teams, and some
- Communication with weather specialists and other students.

- Students work in small groups.
All phases work alone, but all communicate extensively with others.

Assessment Standard A: Assessments must be consistent with the decisions they are designed to inform. (p. 78)

- Assessments have explicitly stated purposes.

- See the Purpose section of activities.

All phases

Assessment Standard B: Achievement and opportunity to learn science must be assessed. (p. 79)

- Achievement data collected focus on the science content that is most

- Curriculum questions; weather recording important for students to learn. 
Table 1 (Continued)

NSES Standard and Fundamental

Concepts
KGS Learning Activities

Phase

Assessment Standard C: The technical quality of the data collected is well matched to the decisions and actions taken on the basis of their interpretation. (p. 83)

- Students have adequate opportunity to demonstrate their achievement

- Curriculum questions, e-mail, data collection, hands-on activities, group

All phases presentations.

Assessment Standard D: Assessments practices must be fair. (p. 85)

Teaching Standard A: Teachers of science plan an inquiry-based science program for their students. (p. 30)

- Work together as colleagues within and across disciplines and grade levels.

Teaching Standard B: Teachers of science guide and facilitate learning.

- Focus and support inquiries while - All activities. interacting with students.

Teaching Standard C: Teachers of science engage in ongoing assessment of their teaching and of student learning. (p. 37)

- Use multiple methods and gather data about student understanding and ability.

Teaching Standard D: Teachers of science design and manage learning environments that provide students with the time, space, and resources needed for learning science. (p. 43)

- Identify and use resources outside the school.
- Written messages, hands-on activities, group presentations.
All phases

Listserv.

- Weather specialists, students from other sites. World Wide Web.
All phases

Most reform experts have documented that teachers are a critical link in the success or failure of educational reforms, including those with emerging technologies (Cuban, 1993; PCAST, 1997; Slavin, Dolan, \& Madden, 1996). Many research studies have documented that teacher beliefs, including about the best pedagogical approaches, are critical to the success of the reform (i.e., Putnam \& Borko, 2000). Taking into account the pedagogy of poverty (Haberman, 1991), along with the understanding of the value of the importance of teacher beliefs, encourages a focus on professional development centered on the enacted curriculum as an essential agent of change (Cuban). Tyack \& Cuban (1995) argued not for top-down or bottom-up approaches to reform, but for change from the inside out, in which policies such as national standards are provided as goals to strive for. Here, the focus of the reform should be ongoing dialogue, iterations of enactment, and reflection with and by cohorts of classroom teachers. Other current thinking in the systemic reform literature resonates with the inside-out approach, with researchers stating, for example, that large-scale educational development projects that address aspects of the school system in concert is the only means of obtaining long-term success (Vinovskis, 1997).

Our professional development with Detroit teachers has followed this systemic adaptation approach to urban educational reform through sustained relationships with urban districts and teachers. As a part of the Center for Learning and Technology in Urban Schools (LeTUS), our program was implemented as one piece of a two-district, two-university partnership that advocates change through the brokering of complex, technology-rich curricular programs between district insiders and university and district personnel. We chose to research the adaptation and use of the KGS program in one of these urban districts (Detroit), in part because the KGS program had already achieved a level of programmatic coherence as a result of seven 
years of implementation in schools nationwide (Songer, 1998). In addition, the LeTUS Center provided our Detroit teachers with an ongoing cohort of urban teachers who were implementing the same or similar technology-rich curricular programs throughout the academic year. In our interpretation of this inside-out approach, efforts were directed toward fostering discussions in and around classrooms as the curricular program was being enacted so that each teacher could reinterpret and rework his or her own best means of reaching these high standards. Although experienced teachers provided guidance for reflective enactment discussions, program support structures also provided multiple avenues for customization of curricular activities, sequences, and roles for teachers and others.

The research presented in this article is one piece of a multi-institution partnership that focuses on local adaptations of one programmatically coherent curricular program in several middle school classrooms within one large urban district. For several years, the LeTUS Center has implemented five curricular programs involving approximately $6 \%$ of the middle school students in this district.

\section{Participants, Programs, and Research Methods}

\section{KGS Program Participants}

The KGS weather program (Songer et al., 1999) was implemented simultaneously in 258 classroom settings with approximately 240 teachers and 10,861 fourth- to eighth-grade students from 40 states. The classrooms were diverse along many criteria including setting, ethnic diversity, and Internet reliability. The classes were in rural (33\%) suburban (13\%), and urban (45\%) settings. In $42 \%$ of the classrooms, at least $50 \%$ were minority students, $20 \%$ of the sites had minority student attendance of $20-50 \%, 38 \%$ of the sites had classes composed of $19 \%$ or less minority students. According to self-reports, Internet access was largely unreliable, with only $6.6 \%$ of sites declaring access very reliable, $25 \%$ saying it was adequate, and $37.6 \%$ indicating poor Internet reliability. Therefore, unlike many other technology reform programs that target high-tech classrooms in more affluent areas, a common profile of a KGS site was an urban school with largely minority students and unreliable Internet technology.

Within this large participant population, we selected six local sixth-grade teachers for focused study of the implementation of the program within the urban Detroit public school district. The Detroit public schools (DPS) serve a population of $95 \%$ minority students, of whom more than $70 \%$ are eligible for free or reduced-price lunches. Students in our focus schools reflected larger district trends.

Table 2 illustrates the characteristics of schools and teachers in this study. Although many characteristics of the focus teachers' learning environments were similar, variability existed in teachers' backgrounds, years of experience, and populations of students in their classrooms. Concerning type of school, five teachers taught in public neighborhood middle schools, and one teacher (Acevedo) taught in a public math and science magnet middle school. Teacher backgrounds also varied, with only three teachers having taken university courses that might support their own understanding of weather concepts. Although Sparks has a master's degree in biological science, she indicated she was not familiar with concepts in atmospheric science and had no experience teaching this content area. Also noteworthy is the high degree of teacher mobility, a factor that is often a challenge in an urban school. Of our focus teachers, only three have been in this district more than 5 years, and several teachers were looking for more lucrative teaching positions during this study. After this program year, both Brown and Sparks left their schools. 
Table 2

Teacher characteristics, backgrounds and instructional freedom (self-report)

\begin{tabular}{|c|c|c|c|c|c|}
\hline & \multirow[b]{2}{*}{$\begin{array}{c}\text { School } \\
\text { Characterisitcs }\end{array}$} & \multicolumn{4}{|c|}{ Teacher Characteristics } \\
\hline & & Major & $\begin{array}{c}\text { Years Teaching } \\
\text { Overall }\end{array}$ & $\begin{array}{l}\text { Years Teaching } \\
\text { in the District }\end{array}$ & $\begin{array}{l}\text { Instructional } \\
\text { Freedom }\end{array}$ \\
\hline Acevedo & Magnet school & Science & 25 years & 10 years & High \\
\hline Brown & Public & Science & 1 year & 1 year & $\begin{array}{l}\text { Moderate, coordi- } \\
\text { nated with the } \\
\text { interdisciplinary } \\
\text { team }\end{array}$ \\
\hline Varney & Public & $\begin{array}{l}\text { Social } \\
\text { studies }\end{array}$ & 10 years & 4 years & $\begin{array}{l}\text { High, coordinated } \\
\text { with the computer } \\
\text { teacher }\end{array}$ \\
\hline Jackson & Public & Math & 31 years & 31 years & Moderate \\
\hline Tam & Public & Science & 26 years & 26 years & $\begin{array}{l}\text { Low, constrained by } \\
\text { the computer } \\
\text { teacher }\end{array}$ \\
\hline Sparks & Public & $\begin{array}{r}\text { Biological } \\
\text { science }\end{array}$ & 4 years & 4 years & $\begin{array}{l}\text { Low with the compu- } \\
\text { ter teacher and } \\
\text { constrained by } \\
\text { administrative } \\
\text { pressure }\end{array}$ \\
\hline
\end{tabular}

Variability also existed in the amount of instructional freedom and support structures experienced by our focus teachers. Many studies have documented the increased pressure placed on all schools, especially urban schools, relative to the standards and testing movements. We observed that our teachers were experiencing reduced instructional freedom over time, as a result in part of the increased demands related to high-stakes testing and the need for increasing amounts of test preparation activities that took away from time for inquiry science or other indepth investigations. Of our focus teachers, we observed that only Acevedo and Varney had a large degree of instructional freedom, including choices of what, how, and when to teach. On a positive note, some teachers were fortunate to have positive support structures that helped them implement a program for the first time. In Brown's school, teachers in language, social studies, math, science, and computers had implemented KGS the previous year and had been working as an interdisciplinary team for the entire school year. Therefore, even though this was Brown's first year at this school and first year teaching KGS, her colleagues' experience provided important insights and guidance. Unfavorable support situations included two schools at which a school rule restricted computer use by any non-computer instructors (Jackson and Tam); and one school with very strong pressure from the building administration to implement new pedagogy that appeared to restrict teachers' creativity and risk taking (Sparks). There is more discussion on teachers' background, students, and support structures in the results section.

\section{Inside-Out Professional Development in Detroit}

The six focus teachers in this study are active members of the multiyear professional development initiative in middle school science implemented through the LeTUS Center. As mentioned previously, KGS is one of several science curricula the LeTUS Center uses to promote technology-rich scientific inquiry throughout sixth, seventh, and eighth grades in all 60 Detroit middle schools. LeTUS teachers participate in Saturday and summer workshops 
throughout the year to explore inquiry pedagogy through the CERA framework for professional development. CERA stands for Collaborative construction of understanding, Enactment of new practices in classrooms, Reflection on practice, and Adaptation of materials and practices (Blumenfeld, Fishman, Krajcik, Marx, \& Soloway, 2000). CERA provides a research environment in which teachers, administrators, and researchers share and discuss inquiryfocused curricula and technological innovations. As CERA reflects professional development in a learning-focused, ongoing sustained manner within school buildings, we believe it is reflective of the inside-out approach to reform discussed earlier.

\section{Inquiry Science Through the KGS Curricular Program}

The Kids as Global Scientists: Weather (KGS) curriculum is an 8-week middle school weather program designed to foster the development of rich explanations and interpretations of complex science phenomena through the development and communication of evidence and investigations of science questions. Student questions are of their own design and are fostered over multiple activities and extended periods of time (Newman, Griffin, \& Cole, 1989). Actual student activities include data collection, data comparison and critique, explanation building, communication of ideas, and real-time predictions.

Building from foundational theories on how children learn (Bransford et al., 2000), the KGS program was created through several years of challenging discussions and iterative research about how to develop programs that exemplify these learning theories as they also use emerging technologies in productive ways. The curriculum maintains programmatic coherence through a series of "core activities" that are suggested as guidelines to follow within each of the 200 nationwide classrooms simultaneously enacting the program. In addition, those in each classroom are encouraged to adapt the program to their own learning goals and audiences through interpretation of the core activities combined with extension activities provided at each time point. Core and extension activities are designed to occur in three sequential phases, each of which builds on the experiences in the previous phases. The KGS program culminates in students' application of their weather-concept understanding toward the prediction and interpretation of current weather events (Songer, 1996). The software developed for this program consists of a CD-ROM and a Web-based threaded discussion board. The KGS CDROM has both a Director-created Web browser for the retrieval and presentation of multiple representations of current weather imagery, and the presentation of archival storms for when Internet connections are unavailable or unreliable (Songer, 1998). The discussion board is organized and facilitated by the research staff and volunteer scientists, and it organizes students into 10 clusters for more focused discussions with peers their own age and with online scientists. Previous research results on KGS programs have demonstrated that students develop a rich understanding of weather concepts (Songer, 1996, 1998), initiate more conversations and have greater control of their own learning (Lee \& Songer, 1998), and have greater time-on-task compared to more traditional middle school science units.

For this implementation with urban teachers, we recognized that the challenges and difficulties identified in Haberman's pedagogy of poverty (1991) might complicate the enactment of the KGS curriculum in urban settings. Therefore, we worked with our urban teachers to recognize specifically the importance of high expectations, the value of students' everyday experiences and ideas, the power of modeling inquiry thinking, and the importance of sharing in discussions with other learners nationwide through the KGS message board. We used the CERA professional development opportunities throughout the year to encourage and re-emphasize these ideas. Although we observed many cases in which these discussions 
appeared useful, we also recognized that it was most likely that such professional development discussions would need additional time for maximum impact.

\section{Instruments and Data Analysis}

The purpose of this study was to examine patterns present across classroom learning environments, actual curricular enactment, and student learning. This study was not intended to demonstrate the effectiveness of the KGS intervention on student learning as compared with other interventions or traditional teaching methods. Rather, we attempted to describe a larger picture of how teachers and students responded to a new technology-rich inquiry program in urban settings so as to increase our understanding of the complicated nature of curriculum enactment against the norms and practices with urban classrooms. Therefore, the primary data sources for this study were written pre- and post-content assessments, class observation forms, and teacher post interviews.

We chose to use both frequent classroom observations and post interviews to gain understanding of classroom dynamics in order to strengthen and validate our findings from either the interview (self-report) or the observations (researcher collected). Although we understood that teachers' self-reports of practices and observed practice are sometimes inconsistent (i.e., Putnam \& Borko, 2000), we believed that data demonstrating consistency in both areas would be stronger than data from either source alone.

Pre- and post-content assessments. Students in all the classes implementing the program in this district were given written pre- and post-content assessments. The assessment instrument contained a total of 14 open-ended and multiple-choice items chosen because of their match to the foundational science content addressed in the program. The multiple-choice items included a sample of seven released National Assessment of Educational Progress (NAEP) items on temperature, weather measurements, and weather chart interpretation and inquiry-focused questions such as on the nature of a hypothesis. The test also included four modified Michigan Education Assessment Program (MEAP) items on fronts, the relationship of pressure to weather patterns, and the interpretation of weather maps. Because this article is focused on trends and patterns across all 19 classes, only analysis of the 11 multiple-choice items will be discussed. The content pre- and post assessment were identical so that repeated-measure analysis of variances (ANOVAs) could be used to illustrate changes in student' science content. Rich casestudy analyses of student learning in particular classes, including both open-ended and multiplechoice analyses, are ongoing and will be discussed in future articles.

Classroom observation forms. In line with Emmer's (1986) observation forms for coding task structures in classrooms, our research team designed a classroom observation form to track the elapsed time, participants, classroom description, and activities performed in classrooms. This instrument was designed to systematically record how the same KGS program was adapted and enacted in a similar or different manner along time and activity dimensions within each teacher's classroom. Graduate student researchers were assigned to each of the six teachers for regular observations of classroom practices and supports. Researchers were required to observe each classroom a minimum of $2 \mathrm{hr}$ a week during at least 8 weeks of the program run time. The six classrooms were observed for 11-27 class periods (50 min each) for a total of 132 observations. At the completion of each observation, a classroom observation form was 
completed by the researcher(s). A complete copy of the observation form is available on request from the article's authors.

Teacher interviews. At the completion of the program, detailed teacher interviews were conducted with all six focus teachers. The interviews were semistructured (Merriam, 1998) and were adapted from previous project interviews developed in concert with the results of current research in teacher reflection and learning (Yorker \& Songer, 1999). The interviews focused on teacher motivation and expectations, challenges and successes, evaluation of student learning and motivation, a characteristic lesson, resources used, and a description of support systems utilized by the teacher, including administrative support, peers, teachers in other locations, and project staff and scientists. On average the interviews lasted $25 \mathrm{~min}$, although they ranged from 20 to $50 \mathrm{~min}$. After the program ended, all interviews were transcribed in full for detailed analysis.

Data analysis of content assessments. Content assessments were coded to reflect the emphasis on patterns among the 19 classes. Using only students who completed both pre- and post tests, 11 content items were analyzed for each student. Repeated-measure ANOVAs were used to illustrate changes in students' science content by teacher.

Analysis of classroom observation forms and teacher interviews. Once the program was complete, researchers adapted the qualitative analysis protocol of Chi (1997) for the analysis of the two types of qualitative data: teacher interviews and the coding of the 132 observation forms. Beginning with the coding of the observation forms, we followed Chi's (1997) eight functional steps for coding qualitative data, including sampling the data, reducing the data, and choosing a coding scheme, which in our case was the development of categories. Once preliminary categories were determined, we coded each classroom for all school factors and then checked and rechecked data sources for consistency. As mentioned, we used our multiple data sources to develop measures of validity. Patterns that emerged were checked for consistency with interview data, and discrepant cases were discussed among the classroom's primary researcher and other researchers until consensus was reached. In addition, three other data sources were used to strengthen the information and patterns emerging from primary data sources. These sources included data from the LeTUS staff on the degree of technological readiness; message-board data, to document students' degree of online correspondence with other students; and records of attendance and involvement of teachers in the teacher workshops. Each classroom was coded on every factor using qualitative evaluations having a 3-point scale (low, moderate/average, high). Figure 1 displays the results that were consistent across data sources. Table 4 presents the coding rubric for data in Figure 1.

\section{Results: Were Classroom Environments Supportive for Inquiry Pedagogy?}

We analyzed our data to explore whether the first year classroom environments were supportive of inquiry pedagogy - in other words, to determine if our patterns reflected the challenges commonly experienced by urban teachers (i.e., Haberman, 1991), or if they more accurately reflected an environment that might foster inquiry learning, such as allowing greater student ownership of learning, questioning, and of other dimensions of inquiry pedagogy. Our data reflect information collected by both qualitative and quantitative research methods. We 


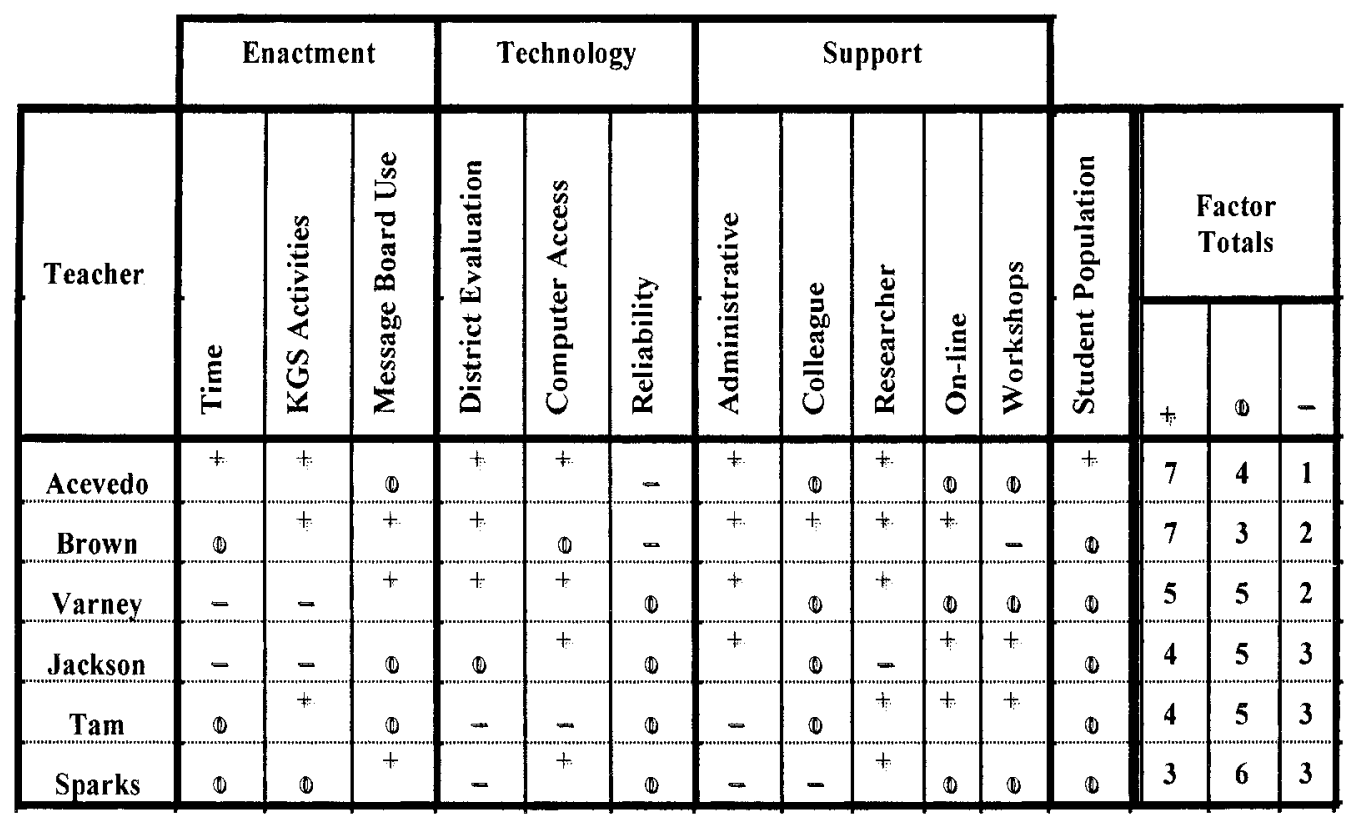

Figure 1. Enactment and school factor schematics by teacher.

combined methods to be able to describe both larger student outcome trends, as well as to describe important characterizations of classroom environment factors that might or might not be conducive to inquiry learning. For each case, a team of three researchers discussed the trends observed by analysis of the observation forms, student learning data, and teacher interviews. This resulted in the most coherent profile possible.

\section{Quantitative Data: Student Learning Outcomes}

We looked at patterns evident from statistical analysis of 19 sixth-grade classes of our six focus teachers on pre- and post-content assessments. Table 3 shows student scores on these items by class and as a group. Note that all classes show statistically significant differences from pre- to post assessment on the measures of science content and science inquiry, and the 19 classes as a group also demonstrate statistically significant differences from pre- to post assessments.

\section{Qualitative Data: Case Studies of Each Classroom}

Following are short narratives that articulate information collected from teacher interviews and classroom observations of each of the six focus teachers and their classrooms. We present our cases in rough order, from the classrooms we consider were most favorable to inquiry pedagogy to those most challenged.

Acevedo's classroom and students. As reflected in Table 3, Table 4, and Figure 1, of the six teachers studied, Acevedo appeared to have the most optimal teaching conditions. At her magnet school, she taught a selected population of students with demonstrated interest in math and science. Her class size was significantly smaller than the district average. Our data show several 
Table 3

Class pre- and post assessment results

\begin{tabular}{lcccccccc}
\hline & Acevedo & Brown & Jackson & Varney & Tam (1) & Sparks & $\begin{array}{c}\text { Tam } \\
(2 \& 3)\end{array}$ & All \\
\hline $\mathrm{N}$ & 19 & 96 & 53 & 54 & 30 & 128 & 43 & 423 \\
Preassessment & 5.97 & 4.09 & 3.34 & 3.96 & 4.67 & 4.52 & 3.37 & 4.17 \\
$\begin{array}{l}\text { (standard } \\
\quad \text { deviation) }\end{array}$ & 2.37 & 1.73 & 1.89 & 1.74 & 1.49 & 1.57 & 1.43 & $1.83^{*}$ \\
$\begin{array}{l}\text { Postassessment } \\
\text { (standard }\end{array}$ & $8.05^{*}$ & $5.59^{* *}$ & $5.06^{* *}$ & $5.22^{* *}$ & $6.40^{* *}$ & $5.06^{*}$ & $3.79^{*}$ & $5.23^{* *}$ \\
$\quad 1.55$ & 1.82 & 2.41 & 2.09 & 2.14 & 1.82 & 1.58 & 2.09 \\
$\quad$ deviation) & & & & & & & & \\
\hline
\end{tabular}

${ }^{*} p<.01$.

${ }^{* * *} p<.001$.

important consistencies in her thinking with what we were observing in her classroom. First, Acevedo believed that enacting this program would be beneficial to both her own learning and the learning and motivation of her students. For example:

A: It sounded so exciting that I wanted to do it.

I: What benefits did you see?

A: The first thing that caught my attention was that they were talking about the children being able to write, and I know how much the children need to write.... Also the weather is a part of the fifth-grade [district curriculum standards].... And using technology, I thought it would be more interesting for them and for me to teach, actually.

[The KGS program] caused the kids to have a great enthusiasm for learning. ... Kids were always excited.... Another expectation I have... is that they would gain selfesteem.... I think this made them feel very special and that their self-esteem was raised tremendously because, um, they had someone else who cared about them, and they really felt good about themselves. They would smile in the halls; they was, like, KGS today !!... And it helped attendance for many of them, 'cause they knew the days they were gonna do KGS, and it was, like, I'll be there for KGS.

Our observations demonstrated that she was able to enact a majority of the program's activities, that students were engaged in the learning activities, and that she had good access to computers, even if the reliability of the network was inconsistent. We also observed strong administrative and researcher supports; therefore, allowing her to feel her work to enact this program was valued. In her interview Acevedo articulated the importance of administrative support in her enactment of programs such as ours when she stated,

I'm honored when I'm asked to do something other than what I normally do [like the KGS program] ... because it shows me that the district and those that are my superiors have confidence in me. And when they ask me, especially with a new program... they will allow me to work the program in order to get some data that will be used for the district. Well, I feel really honored that I was asked.

Not surprisingly, the students in Acevedo's classroom demonstrated very strong pre- and post scores on our content and inquiry assessments, and they showed significant gains and the highest average post score gains of any DPS classroom. 
Table 4

Classroom and school factors coding rubric

\begin{tabular}{|c|c|c|c|}
\hline Category & Sub Category & Data Source & Criteria \\
\hline \multirow[t]{3}{*}{$\begin{array}{l}\text { Curriculum and } \\
\text { enactment } \\
\text { time estimates }\end{array}$} & Total enactment time & Observation & $\begin{array}{l}+ \text { more than } 8 \text { weeks } \\
.8 \text { weeks } \\
- \text { less than } 8 \text { weeks }\end{array}$ \\
\hline & $\begin{array}{l}\text { Implementation of founda- } \\
\text { tional KGS activities } \\
\text { (total }=11 \text { activities) }\end{array}$ & Observation & $\begin{array}{l}+9-11 \\
\cdot 7-8 \\
-<6\end{array}$ \\
\hline & $\begin{array}{l}\text { Implementation of founda- } \\
\text { tional KGS correspondence } \\
\text { (i.e., gross evaluation of the } \\
\text { frequency of messages } \\
\text { posted on the message } \\
\text { board per class) }\end{array}$ & $\begin{array}{l}\text { Message board } \\
\text { database }\end{array}$ & $\begin{array}{l}+ \text { high-average } 4 \text { or more } \\
\text { class sets per program } \\
\text { medium-2-3 class sets per } \\
\text { program } \\
-1 \text { or fewer class sets per } \\
\text { program }\end{array}$ \\
\hline Technology & $\begin{array}{l}\text { District evaluation of } \\
\text { technological readiness }\end{array}$ & $\begin{array}{l}\text { LeTUS Center } \\
\text { evaluations, } \\
1 / 99\end{array}$ & $\begin{array}{l}+ \text { high degree of readiness } \\
\text { midlevel of readiness } \\
- \text { low degree of readiness }\end{array}$ \\
\hline \multirow[t]{2}{*}{ At-school setting } & Computer access & Observation & $\begin{array}{l}+<50 \% \text { observed reliability } \\
\cdot \sim 50 \% \text { observed reliability } \\
->50 \% \text { observed reliability }\end{array}$ \\
\hline & $\begin{array}{l}\text { Technology reliability for } \\
\text { curriculum enactment }\end{array}$ & $\begin{array}{c}\text { Observation/ } \\
\text { interview }\end{array}$ & $\begin{array}{l}+ \text { no restrictions } \\
\cdot \text { minor restrictions } \\
- \text { major restrictions }\end{array}$ \\
\hline \multirow[t]{5}{*}{ Support } & Administrative support & $\begin{array}{l}\text { Observation/ } \\
\text { interview }\end{array}$ & $\begin{array}{l}\text { + helpful/satisfactory support } \\
\text { - not a factor } \\
\text { - limited teacher's curricu- } \\
\text { lum enactment }\end{array}$ \\
\hline & Colleague support & $\begin{array}{c}\text { Observation/ } \\
\text { interview }\end{array}$ & $\begin{array}{l}\text { + helpful/satisfactory support } \\
\text { - not a factor } \\
\text { - limited teacher's curricu- } \\
\text { lum enactment }\end{array}$ \\
\hline & Researcher support & $\begin{array}{l}\text { Interview/ } \\
\text { classroom } \\
\text { supporter's } \\
\text { account }\end{array}$ & $\begin{array}{l}\text { + helpful/satisfactory support } \\
\text { - not a factor } \\
\text { - limited teacher's enactment }\end{array}$ \\
\hline & $\begin{array}{l}\text { Online support (e-mail with } \\
\text { researcher or manager, fax, } \\
\text { teacher Listserv, teacher } \\
\text { message board) }\end{array}$ & $\begin{array}{l}\text { Records of } \\
\text { teachers' use of } \\
\text { communication } \\
\text { tools }\end{array}$ & $\begin{array}{l}+ \text { use more than one resource } \\
\text { during program } \\
\text { - use at least one resource } \\
\text { - use none }\end{array}$ \\
\hline & $\begin{array}{l}\text { Workshop experience } \\
\text { (summer }+3 \text { Saturday } \\
\text { workshops) }\end{array}$ & $\begin{array}{l}\text { Records of } \\
\text { workshop } \\
\text { attendance }\end{array}$ & $\begin{array}{l}+ \text { participated on all four } \\
\text { occasions } \\
\text { missed one } \\
- \text { missed two or more }\end{array}$ \\
\hline $\begin{array}{l}\text { Student } \\
\text { population }\end{array}$ & Nature of student population & $\begin{array}{l}\text { Observation/ } \\
\text { interview }\end{array}$ & $\begin{array}{l}+ \text { selective for academic } \\
\text { talents } \\
\text { - nonselective, mixed abilities } \\
- \text { unusually challenging } \\
\text { population }\end{array}$ \\
\hline
\end{tabular}

Note. All classifications are listed as N/A when corresponding evidence was not available. 
Brown's classroom and students. From our observations, interview data, and student learning results, we came to believe that the opportunity to enact inquiry pedagogy was second highest in Brown's classrooms. Brown was a new teacher, but she was also placed within a strong interdisciplinary team, all of whose members had participated in KGS in previous years. The support structure allowed her to carry out a majority of the activities, and according to both selfreport and the statistical data, her students appeared to learn a great deal about the science concepts studied:

I think the kids learned a lot about weather.... I think that some of them really got some complex ideas about weather and kind of the idea being that it is this huge system with lots of different factors.... I liked the forecasting activity, too. I thought it was really neat that the kids could come in and ... look at current weather maps and make a prediction and then come in the next day and find out if they were right or not. I think they really enjoyed that, and ... they learned a lot from having to incorporate... different pieces of information. So I think that was really positive.

However, the interview and observation data consistently showed that the lack of reliable Internet connections resulted in student and teacher disappointments, as poor connections reduced the frequency of performance of learning activities in which artifacts, ideas, and realtime prediction activities were shared. A member of Brown's interdisciplinary team commented on the learning potential of these sharing activities:

It's in programs like KGS that [kids are] offer[ed] ... a chance to compose messages, talk
to other kids, find out ... that other kids are not that different, even if you live in "Murder
City" or whatever you want to call Detroit... There is an opportunity to see that there is a
use for all of this stuff you are learning in school.... Last year we used the discussion
boards a lot more, ... and the language arts teachers noted phenomenal improvement in the
kids' desire to write properly... It really brings the computer into the proper use rather
than just baby-sitter or something like that. Kids are actually creating something.

Varney's classroom and students. The classroom factors in Varney's classroom reflected both supportive and nonsupportive conditions for inquiry pedagogy. Varney is an ESL teacher in a bilingual school and does not have formal education in science. His teaching was interrupted by his 2-week vacation, and he was strongly pressured to prepare his students for upcoming standardized tests; these activities limited the time available for KGS activities. Nevertheless, he was very excited about participating in our program, both for the potential learning by his students and for himself:

I did experience the unfortunate timeliness of KGS. We had 2 weeks off. We had a winter break ... and a Easter/spring break. And that was unfortunate. We had to play a lot of catch up.... That was probably the biggest problem I encountered.

I was very excited as a matter of fact. [I chose to teach KGS] knowing that since I teach ESL students, my job becomes a little more complex. It requires a lot of translation and type of work that other teachers may not require. I usually have reservations about some things that I do... but at this point...my attitude is that if it is exciting for students ... then I'm willing to give it a try.... Personally, I learned a lot."

Table 3 shows that Varney's students also learned a lot, with strongly significant gains from pre- to post tests. On balance, our observations show that Varney's support structures were 
reasonable but not extensive, and in our interview with him he articulated his need to take initiative to educate his administrators about the value of his work with programs like this one:

"Often times I'm not asked how things are going. What I do instead, especially during staff meetings, I will just volunteer information to let them know what we are doing.... It would behoove them to know that our students are challenged and succeeding."

Jackson's classroom and students. Observation and interview data on Jackson's classroom also show both positive factors and challenging factors in the implementation of inquiry pedagogy. First, Jackson only met with his science students 3 days a week, thereby significantly reducing the available time for KGS inquiry. Our observations show that Jackson's students had restrictions on how much time they could spend in the computer lab, thereby also limiting the available time for the learning activities that involved computers, although he had a set of older computers right in his classroom. Like the situation for the others, the computer network in his building was not reliable.

The positive factors included Jackson's observations that when students did KGS activities, they helped each other more and they took more initiative outside class time: "Another [advantage] would be [that] students help one another more...during the KGS program. ... Students also take more initiative outside of class time. I found this interesting. It involves homework completion, doing extra research via the Internet, or ... writing quality is better when they use the message board. It forces them to update their grammar." Concerning challenges faced, Jackson often found himself as the leader of such reforms in his buildings and, as a result, did not have many colleagues to assist him. When asked if other teachers in his building encouraged him to try new ideas, he stated, "No. As a matter of fact, I encourage them."

Tam's classroom and students. The observation, interview, and test scores from Tam's classroom showed two classes had challenging management problems, and one class had more favorable classroom dynamics for inquiry learning. Nevertheless, all three of Tam's classes demonstrated significant learning gains, as shown in Table 3.

In interviews, Tam articulated several positive benefits of teaching KGS, including students being able to guide their own learning, perform better on high stakes tests, and technological literacy. In addition, Tam had interesting observations about how a shift to the inquiry-learning approach in KGS benefited some students who were low achievers in other subjects, whereas it challenged the high achievers because the learning approach was different than what they were used to: "I think that letting them explore on the computer is the only way it can be done. You can't tell them, you know, now go here and go there, and do this and do that. It has to be allowing them to learn for themselves." And later,

[My partner-teacher] noted that she has had students that have done nothing all year and have done this and done well. She has had some students who were... A caliber who are used to reading and regurgitating, and they found this challenging because they didn't know what was expected of them.... So she found that it was a challenge for the bright students ... and then she found these hardcore few-that I tend to ignore actually—-[who] came on board and have done very well. Some of them for the first time ever perhaps are going to get a C or D.... I think the kids like it [the KGS program], and therefore they are going to do more than were we to do it any other way.

Tam's challenges, however, were not slight. One of Tam's greatest struggles was the inadequacy and unavailability of her computer lab. Tam's classes averaged 34 students, and the 
computer lab held only 17 chairs. In addition, lab access was restricted to those with a single key, to which Tam did not have access. Her students had no computer experience prior to this program. Tam discussed these challenges: "I could handle 17 computers and 34 kids if they could all sit down. But having 17 chairs and 34 kids becomes a real challenge, as some of them ended up kneeling.... Our kids do not have computers. They do not have computer courses."

By her own account and ours, Tam persisted despite large challenges. Her perseverance clearly had positive benefits, as it allowed her learning goals of student exploration of ideas and computer fluency to be realized.

1: With all these challenges, what made you keep going and still want to continue to try out as many activities as you did?

$T$ : Because I liked, I really liked the curriculum.... To use the technology to let them explore and find answers for themselves - that was one of my goals, and I think that was something they really enjoyed.... I think [KGS] has a lot of rewards for the kids. [That's] the part I think they were missing in a regular curriculum, where they are not posting their data or looking at someone else's data or seeing what's happened to the high pressure or what is happening to the sky. It brings it more into their world.

Sparks's classroom and students. The teacher who had the largest challenges to inquiry pedagogy, according both to her and our observations was Ms. Sparks. This teacher was partnered with Marks, the computer teacher, to teach KGS. From our observations, and interviews, we developed a classroom profile that showed many areas not favorable to inquiry pedagogy, including inadequate computer lab space, inadequate time to enact the inquiry program, little administrative support, and unreliable networks. In interviews, Sparks and Marks both described how they were not asked whether they wanted to participate in the program, and they did not find out they were teaching it until a week before the program began.

$S$ : It was not a decision of mine. I was just informed.

I: Did you feel you had a choice whether or not to participate?

$M$ : No, it was clear that I did not have a choice at all. . . . It had already been decided that I was going to be in it, but no one let me know.

$I$ : At that time did you see any benefit in participating?

$M$ : No... I had no idea what KGS was.

The challenges of Sparks and Marks to get adequate space and to feel supported in this work continued throughout the enactment.

M: The major challenges had nothing to do with the KGS program....I wrote [the principal] 3-5 different letters requesting to see her because I had concerns about the computer lab. The other side of the room was teaching a different content area than KGS, and at times almost every day.... I'd have to literally cup my hands and yell instructions to the students because they could not hear me.

$S$ : Maybe it seemed like I lost my enthusiasm over the program, [but] it wasn't because of KGS or from you. It's just that from things happening inside of the school, I just wanted to finish.

M: I did not get any support at all. In fact, even to hear something negative would've been at least an acknowledgement that I was teaching the program. There was nothing said negatively, nothing said positively. It was as though I was invisible-which is zero support. I'd rather have something negative then to be just nothing. 
Interestingly, both Sparks and Marks adopted, to use their own words, "an open mind" about these challenges and came to recognize many positive benefits of the program for their students.

M: Overall, I'm very positive about the KGS program. My basic philosophy through all of teaching is that I want to make education relevant for our kids, I want to make it real for them. I think studies have shown that even our honor students live somewhat a schizophrenic life. There's school, and there's the real world. And I'm trying to connect these two together. I saw KGS, once I started reading about it as an opportunity to have real, live data and things that the kids could understand in school related to home.

$M$ : The KGS software was very good. I liked the idea of having a weather specialist that students could talk to. They were very excited about that, about going all over the world. They wanted to get out of the United States and into other countries. The kids really enjoyed, really enjoyed more than I thought, talking back to each other.

\section{Discussion}

This study was designed to explore the barriers to technology-rich inquiry pedagogy in urban science classrooms. Although a handful of studies have researched the impact of inquiryfocused pedagogical approaches on African American or urban science students, few studies have researched initiatives that use technological-rich science programs to challenge both the pedagogy of poverty and the digital divide.

We began with a discussion of what might be considered some barriers to inquiry pedagogy in urban science classrooms, as identified by Haberman (1991), Barton (1998), and others. We return now to this discussion, adding insights from our study.

\section{Were Haberman's Constraints Observed in KGS Classrooms?}

Our case studies support the ideas presented by Haberman (1991) and others that urban teachers have tremendous constraints that challenge their ability to implement pedagogy of any kind, including inquiry pedagogy. The specific constraints we observed are:

- Inadequate space, equipment, and materials (no chairs, no key—Tam; noisy roomSparks/Marks);

- Inadequate prep time to plan and reflect on a new program (all teachers, but especially Varney, Jackson, and Sparks/Marks);

- Low levels of science content or computer knowledge and training (many, particularly on content background helpful to guide the exploration of current weather events);

- Large class sizes (all but Acevedo);

- High levels of teacher and student mobility (all);

- Limited instructional freedom and/or lack of administrative support (Varney, Jackson, Sparks); and

- Unreliable Internet connectivity (all).

According to Haberman (1991), if these constraints are prevalent, it can result in predictably difficult student behaviors and resulting teacher burnout: 
The classroom atmosphere created by constant teacher direction and student compliance seethes with passive resentment that sometimes bubbles up into overt resistance. Teachers burn out because of the emotional and physical energy that they must expend to maintain their authority every hour of every day. The pedagogy of poverty requires that teachers who begin their careers intending to be helpers, models, guides, stimulators, and caring sources of encouragement transform themselves into directive authoritarians in order to function in urban schools (p. 291).

Although two of our six teachers did leave the district after our program, in general, we did not document student behaviors or teacher burnout reaching these high, volatile levels. We hypothesize that part of the reason these extremes did not occur might be because of several positive dimensions of the KGS experience for our teachers, many of which influenced their beliefs and practices. Next, we present a characterization of positive values attributed to the KGS program enactment by the teachers.

\section{What Positive Values Did the KGS Program Provide for Students and Teachers?}

From our data, as outlined by teachers in our study, we derived six positive values of the KGS program. These included: relevance, learning benefits for all students, learning benefits for special populations of students, learning benefits for teachers, enthusiasm for learning, and developing fluency with technology.

Relevance. Barton's, (1998) work outlined how many students in poverty do not find classroom science interesting or relevant to their lives. According to our teachers, one of the strongest benefits of the KGS program was the many opportunities for students to find personal meaning and relevance in KGS classroom science. Acevedo, Brown, Marks, and Tam all described the enthusiasm students experienced when they used Internet technologies to track live storms, share their scientific understandings and personal experiences with other students, use message-board conversations to combat stereotypes, and in other ways connect the worlds of their own experience, scientific reasoning, and others. We believe the program allowed students to find science relevant as a result of the open-ended nature of inquiry activities, the control students' experienced in their own learning including asking their own questions about storms, and the providing of activities and an enthusiastic audience for students' scientific ideas.

Benefits to student content and inquiry science. Another strong benefit was the teachers' belief that students were learning important science content about weather systems, forecasting, and data analysis, and were developing explanations and writing skills through the online message-board conversations. Acevedo, Brown, Varney, Jackson, and Tam all described the value of these learning opportunities and the positive challenges such activities gave students, allowing many to strive toward their full potential, as compared to more traditional, less challenging curricula. In addition, Brown, Tam, and Jackson specifically described important dimensions of inquiry learning they experienced in their classrooms. These included the value of students' creation of their own products (Brown), finding answers for themselves (Tam), and helping each other to learn (Jackson).

Learning benefits for special populations of students, including new challenges. Varney and Tam described how the inquiry and Internet-sharing dimensions of the KGS pedagogical 
approach provided challenging opportunities for new learning among special groups of students. Tam described how some of her lowest achievers would earn a C or D "for the first time ever." She also described a result common in inquiry-learning programs, in which the high-achieving students are challenged in new ways as a result of being asked to do tasks that require thinking rather than rote memorization or other forms of more routine learning. Varney liked adapting KGS to his bilingual classroom and the resulting learning that occurred, despite the extra demands this placed on him.

Benefits to teacher learning. Several teachers described how a program that tracks current science and uses technology to foster inquiry thinking also provides challenging and important opportunities for the teachers' own learning, of both science and technology. Marks was pleased that, even though she did not volunteer for KGS, as a result of the experience, she gained an important understanding of how to use technology. Other teachers who mentioned this benefit include Acevedo, Brown, Varney, and Tam.

Student enthusiasm and strong self-esteem. Acevedo described the impact on her students' enthusiasm for learning and self-esteem of having her students participate in a program that used new technologies and had high visibility in the school. A strong motivation for her participation was the desire to help her students feel valued and special, partly to provide support for students dealing with the less positive factors common in their lives outside the classroom. Similarly, Brown described the importance of her students being able to combat negative stereotypes about Detroit, such as its being called the "Murder City," through interactions with students and scientists online. Jackson valued students' high interest in the program, as it facilitated extra time on homework and initiative outside class time.

Developing greater fluency with technology. Many teachers discussed the value of helping students without access to computers at home or in school to become fluent with technology. Because of this lack of technology access, these students could be described as on the have-not side of the digital divide, and many teachers recognized the large disadvantage a lack of computer experience might present for their students in the future. Acevedo and Tam discussed the importance of their students becoming fluent in an increasingly high-tech world. Several teachers valued the role technology played in KGS in fostering higher-order thinking, student questioning, and student sharing of ideas and products, rather than routine drill and practice activities.

On balance, our study has provided additional evidence that despite efforts like KGS, the digital divide persists in many urban areas. Every teacher described his or her frustrations with Internet reliability and how unreliable access diminished the potential impact of inquiry science on student learning. Despite the high degree of Internet access nationwide, educational institutions in urban areas like Detroit still face tremendous hurdles from local Internet service providers and utility companies in obtaining reliable Internet connections to school buildings. Programs such as KGS can provide resources such as the canned storms on our CD-ROMS that allow students and teachers to continue activities even when Internet connections are down (Songer, 1998). However, we know that although we provided strong support and opportunities for students to experience higher-order thinking, our goal of combating the "meaningful use" dimension of the digital divide was often underrealized because of unreliable networks and poor resources. Technology cannot play an essential role in changing both the what and the how 
students learn until the basic problems of network reliability and support for technology are resolved in urban settings.

\section{Summary}

Our study has provided evidence that a systematic program for fostering inquiry including the accompanying professional development activities can overcome many of the norms and practices commonly referred to as the pedagogy of poverty, including norms on how science is taught and learned and how technology is used for learning. Although significant learning results occurred in every classroom, we also discovered several persistent barriers to our work, including several cases of inadequate space and materials, inadequate time, low content knowledge among teachers, large class sizes, high student and teacher mobility, limited instructional freedom, and unreliable Internet connectivity.

Our work suggests that even the most innovative pedagogy and professional development approaches cannot overcome many of these barriers. In the classrooms where these barriers were large and numerous, our approaches showed gains but inevitably did not realize their full potential.

In contrast, systematic support structures such as LeTUS for working with professional development, administrators and technology, and classroom supports provided by KGS staff helped teachers and us to chip away at many of the barriers and move toward stronger learning outcomes. Although we did not run our program in Detroit schools that were not part of the LeTUS structure, we speculate that without the multiple avenues for support and reflection LeTUS provided, the learning outcomes and positive benefits we observed would be severely reduced.

One goal of this study was to try to understand what role technology plays in contributing to either the observed challenges or learning benefits. In reviewing the observed list of constraints, explained above, only the last constraint, unreliable Internet connectivity, was a direct result of the presence of technology in our program. The other six constraints are those common in urban classrooms across the nation and, as such, would likely be present in any curricular reform program implemented in those classrooms.

Overall, we observed six values that the KGS program added to inquiry pedagogy in these classrooms. These are relevance, student content and inquiry learning, learning by special populations, teacher learning, enthusiasm, and fluency with technology. We speculate that each of these benefits would not be present without the technology components of our program. For example, we expect that the Internet conversations and real-time weather forecasting allowed students to break down stereotypes about Detroit and provide their own views on tomorrow's weather in a focus city, therefore allowing them to find value and relevance in their studies. Student learning gains in content and inquiry would have been different without live weather maps, conversations with online scientists, and opportunities for students' own questions and forecasts. The sharing of products across the message boards contributed to special populations' motivation to explore science questions of their own design, and to practice online writing for valued audiences, including scientists. Teacher learning was facilitated through the challenge of learning about current weather events, online conversations with scientists about content issues, and teachers' abilities to find support for increasing fluency with technology. We speculate that students' increased enthusiasm was a result of students' abilities to recognize that their ideas were important and valued and to track current scientific events as they unfolded-all of which encouraged students to be excited about the program. Therefore, when we ask what role technology played in contributing to the learning experience, we can conclude that while 
technology was not able to overcome many of the classroom barriers that are most persistent such as class size, mobility, inadequate space, or reduced instructional freedom, we do believe that technology was an essential component of all of the observed learning benefits discussed. We encourage the continuation of studies such as this one that explore the barriers common in urban classrooms that contribute both to the pedagogy of poverty and the digital divide, as well as the exploration of best mechanisms to challenge those barriers. We present this study as a contribution to an evolving discussion on the mechanisms needed to overcome the barriers and realize the opportunities for classroom-based, technology-rich inquiry pedagogy.

\section{References}

Atwater, M., \& Wiggins, J. (1995). A study of urban middle school students with high and low attitudes towards science. Journal of Research in Science Teaching, 32(6), 665677.

Barton, A.C. (1998). Reframing "science for all" through the politics of poverty. Educational Policy, 12, 525-541.

Becker, H. (2000). Who's wired and who's not: Children's access to and use of computer technology. Children and Computer Technology, 10(2) .

Becker, H., \& Riel, M. (2000). Teacher professional engagement and constructivistcompatible computer use. Report \#7. University of California, Irvine, Irving, CA, and University of Minnesota, Minneapolis, MN: Center for Research on Information Technology and Organizations.

Blumenfeld, P., Fishman, B., Krajcik, J., Marx, R., \& Soloway, E. (2000). Creating usable innovations in system reform: Scaling-up technology-embedded project based science in urban schools. Educational Psychologist, 35(3), 149-164.

Bransford, J.D., Brown, A.L., \& Cocking, R. (2000). How people learn: Brain, mind experience and school. Washington, DC: National Academy Press.

Chi, M.T.H. (1997). Quantifying qualitative analyses of verbal data: A practical guide. The Journal of the Learning Sciences, 6(3), 271-315.

Clinton, B. (1999, September 30). Remarks from the opening session of the 1999 National Education Summit. Received from www.summit99.org/jointvirtual/speechclinton.html.

Cuban, L. (1993). The lure of curriculum reform and its pitiful history. Phi Delta Kappan, 75(2), 182-185.

Emmer, E. (1986). Academic activities and tasks in first-year teachers' classes. Report No. 6025. Austin, TX: University of Texas, Research and Development Center for Teacher Education.

Haberman, M. (1991). The pedagogy of poverty versus good teaching. Phi Delta Kappan, 73, 290-294.

Hoffman, D.L., \& Novak, T. (1999). The evolution of the digital divide: Examining the relationship between race to internet access and usage over time. Retrieved from www2000.ogsm.vanderbilt.edu/.

Kahle, J., Meece, J., \& Scantlebury, K. (2000). Urban African-American middle school science students: Does standards-based teaching make a difference? Journal of Research in Science Teaching, 27(9), 1019-1041.

Knapp, M. (1997). Between systemic reforms and the mathematics and science classroom: The dynamics of innovation, implementation and professional learning. Review of Educational Research, 67(2), 227-266. 
Lee, S.Y., \& Songer, N.B. (1998). Electronic Discourse as an essential component for building and sustaining electronic community of science learners. Proceedings of the Third International Conference on the Learning Sciences (ICLS '98).

Linn, M.C., Lewis, C., Tsuchida, I., \& Songer, N.B. (2000). Beyond fourth grade science: Why do US and Japanese students diverge? Educational Researcher, 29(3), 4-14.

Merriam, S.B. (1998). Qualitative research and case study applications in education. San Francisco: Jossey-Bass.

National Research Council. (1996). National Science Education Standards. Washington, DC: National Academy Press.

Newman, D., Griffin, P., \& Cole, M. (1989). The construction zone: Working for cognitive change in school. Cambridge, England: Cambridge University Press.

PCAST. (1997). Report to the president on the use of technology to strengthen K-12 education in the United States. March. Retrieved from www.ostp.gov/PCAST/k-12ed.html.

Pea, R. (1998). Debate with Larry Cuban on reform and technology. Retrieved from www.tappedin.sri.org.

Putnam, R., \& Borko, H. (2000). What do new views of knowledge and thinking have to say about research on teacher learning? Educational Researcher, 29(1), 4-15.

Slavin, R., Dolan, L., \& Madden, N. (1996). Scaling up: Lessons learned in the dissemination of success for all. Paper presented at the annual meeting of the American Educational Research Association, New York, NY, 1996.

Songer, N.B. (1996). Exploring learning opportunities in coordinated network-enhanced classrooms: A case of kids as global scientists. The Journal of the Learning Sciences, 5(4), $297-$ 327.

Songer, N.B. (1998). Can technology bring students closer to science? In Tobin, K., \& Fraser, B. (Eds.), The international handbook of science education. (333-348). Dordrecht, The Netherlands: Kluwer.

Songer, N.B., Devaul, H., Hester, P., Crouch, S., Kam, R., Lee, H.S., \& Lee, S.Y. (1999). Kids as global scientists: Weather!: An eight-week inquiry curriculum for middle school atmospheric science. The University of Michigan.

Teel, K.M., Debruin-Parecki, A., \& Covington, M. (1998). Teaching strategies that honor and motivate inner-city African-American students: A school/university collaboration. Teaching and Teacher Education, 14(5), 479-495.

Tyack, D., \& Cuban, L., (1995). Tinkering towards utopia: A century of public school reform. Cambridge, MA: Harvard University Press.

Vinovskis, M. (1997). An analysis of the concept and uses of systemic educational reform. American Educational Research Journal, 33(1), 55-85.

Yorker, C., \& Songer, N.B. (1999). The challenges and affordances of enacting a reformminded middle school science and technology program: Teachers' voices on creating new roles. Paper presented at the Annual Meeting of the American Educational Research Association, Montreal, Quebec, Canada. 